\title{
OS EFEITOS DA PERDA DE PESO RÁPIDA EM ATLETAS DE ARTES MARCIAIS
}

\section{ARTIGO ORIGINAL}

MARTINS NETO, João Victor ${ }^{1}$, CANTÃO, Elbert Wander ${ }^{2}$

MARTINS NETO, João Victor. CANTÃO, Elbert Wander. Os efeitos da perda de peso rápida em atletas de artes marciais. Revista Científica Multidisciplinar Núcleo do Conhecimento. Ano. 06, Ed. 12, Vol. 08, pp. 148-167. Dezembro de 2021. ISSN: 2448-0959, Link de acesso: https://www.nucleodoconhecimento.com.br/educacaofisica/perda-de-peso

\section{RESUMO}

Em torneios de Artes Marciais, artifícios em busca para a perda de peso rápida (PPR) são frequentemente utilizados para conseguir algumas vantagens sobre o adversário. Neste processo, a perda de peso, em muitos casos, é feita de forma extremamente rápida. Diante disso, esta pesquisa tem como problematização: quais as consequências físicas e psicológicas para o atleta que faz uso da PPR? Sendo assim, o objetivo geral desse artigo foi verificar se um grupo de praticantes de artes marciais já fez o uso de alguma estratégia de PPR e mostrar as consequências dessa abordagem. Adotou-se as bases de dados Scielo, ScienceDirect e Google Scholar para construir a revisão de literatura acerca do tema utilizando como fontes de busca as palavras-chave: artes marciais, desidratação, rápida, perda, peso. Foi aplicado, também, um questionário com doze questões de múltipla escolha elaborado via Google Forms e distribuído de forma aleatória. A amostra da pesquisa é constituída por 37 praticantes de artes marciais ( 28 homens e 9 mulheres). Conclui-se que os efeitos colaterais apresentados pelos atletas da amostra que afirmaram ter feito PPR, foram $48 \%$ notaram redução do desempenho atlético, $39 \%$ observaram mudanças no

\footnotetext{
1 Graduado em Educação Física.

${ }^{2}$ Mestrando em Ciências Aplicadas à Saúde (UFJ-GO), Pós graduação em Nutrição Humana e Saúde (UFLA-MG), Graduação em Educação Física (FAGAMMON-MG) 
humor e $13 \%$ perceberam mudanças no comportamento, estes dados são condizentes com os descritos literatura pesquisada. Todavia, mesmo após sentirem efeitos negativos em sua saúde e descobrirem sobre todos os riscos, atletas que fizeram PPR afirmaram que voltariam a repetir tais procedimentos. Para reduzir os efeitos colaterais e os riscos à saúde dos atletas oriundos da PPR, uma abordagem multidisciplinar, composta pelo técnico, preparador físico, nutricionista e psicólogo deve ser adotada para que o atleta consiga uma perda de peso gradual, segura e de médio a longo prazo.

Palavras-chave: Artes marciais, Desidratação, Perda, Rápida, Peso.

\section{INTRODUÇÃO}

Entende-se como esportes de combate todas as modalidades de luta que envolvam dois atletas disputando entre si a vitória. A vitória pode ser determinada por: pontos, perda dos sentidos, desistência ou desclassificação. (LIMA et al., 2010).

Desde a década de 1990, o número de praticantes de esportes de combate aumentou significativamente, principalmente nas modalidades de Jiu-Jitsu, Muay Thai e Mixed Martial Arts (MMA), que mais penetraram na sociedade e desencadearam o processo de popularização. Atualmente, dentro do MMA, o evento de maior destaque é o Ultimate Fighting Championship (UFC). (VASQUEZ, 2013).

Os órgãos responsáveis pela organização das competições de lutas têm adotado uma série de estratégias para manter a saúde física dos atletas, dividindo-os em peso, graduação e faixas etárias semelhantes, além do uso de equipamentos de proteção e cancelamento de mais golpes. (AWI, 2012).

Ademais, em algumas modalidades específicas, como o MMA e o boxe, a pesagem do atleta acontece cerca de 24 horas antes da luta. Alguns eventos de "luta-casada" do Jiu-Jitsu também adotam a mesma estratégia. Porém, na grande maioria das competições de Jiu-Jitsu, a pesagem do atleta é feita momentos antes da luta. Mesmo com essas diferenças, alguns atletas tentam entrar em uma categoria que seja menor 
do que seu peso real, utilizando uma estratégia de desidratação aguda para reduzir seu peso. (SANTOS JÚNIOR, 2016).

É muito comum nos esportes de combate a tentativa de perda de peso rápida (PPR) em período pré-competitivo para que os atletas se enquadrarem em categorias mais leves. Existe uma cultura entre os atletas que os mesmos teriam algum tipo de vantagem sobre seu adversário se lutarem numa categoria de peso inferior à sua própria. (SUNDGOT-BORGEN et al., 2013).

Diante disso, o presente artigo tem como questão norteadora: quais as consequências físicas e psicológicas para o atleta que faz uso da PPR?

A transpiração excessiva é um dos métodos mais comuns usados pelos combatentes no processo de perda de água. Os principais meios utilizados para isso são os exercícios físicos, exposição à sauna, exercícios físicos vigorosos com roupas de plástico e / ou em ambiente quente e úmido. (ROSSI et al., 2010).

A literatura mostra que o uso desses métodos pode levar a redução do volume sanguíneo e plasmático, alterações da função cardíaca, redução das atividades imunológicas, cognitivas e sensoriais, redução do fluxo sanguíneo renal, alterações da função glomerular (maior perda de eletrólitos). (ROSSI et al., 2010).

Baseado nessas informações, o objetivo geral desse artigo foi verificar se um grupo de praticantes de artes marciais já fez o uso de alguma estratégia de PPR e mostrar quais as consequências dessa abordagem.

\section{DESIDRATAÇÃO: UM DOS PRINCIPAIS MÉTODOS UTILIZADOS DE PPR}

A desidratação é uma das principais estratégias utilizadas pela maioria dos atletas. (BRITO et al., 2012). Outras estratégias também são utilizadas, como apontado no mesmo estudo de Brito et al. (2012), realizado em Minas Gerais com atletas de judô, jiu-jitsu, karatê e taekwondo. Independentemente do exercício, 60\% dos atletas relatam usar métodos de PPR, incluindo aumento de exercícios, dieta hipocalórica, 
redução de carboidratos e líquidos, uso de saunas ou roupas de plástico e uso de laxantes ou diuréticos. Nos últimos tempos, devido à realização de exames antidoping, estes dois últimos métodos citados são menos praticados (FABRINI et al., 2010). Apesar de existirem inúmeros métodos de PPR, o foco dessa revisão será na desidratação, discutindo suas consequências e efeitos para os atletas.

A desidratação é uma condição fisiológica causada pela perda de água no corpo a longo prazo. Pode afetar as funções fisiológicas e a temperatura corporal, causando complicações e degradação do desempenho durante o exercício (WEBBER et al., 2009).

A desidratação pode levar a uma diminuição do volume sanguíneo, tornando os atletas mais suscetíveis a hipotensão postural e colapso (IDE, 2004). O baixo volume sanguíneo também está relacionado à redução da ejeção cardíaca, que leva à diminuição do fluxo sanguíneo para a pele, o que tem impacto negativo na dissipação de calor. Quanto maior o grau de desidratação, menor a capacidade de redistribuir sangue para a área circundante, menos sensível o hipotálamo à sudorese e pior a capacidade aeróbia para um determinado débito cardíaco (CARVALHO, 2010).

Existe uma diferença de comportamento entre os sexos durante o processo de perda de peso rápida. Atletas do sexo feminino tendem a ter maiores desconfortos em relação aos atletas do sexo masculino. Acredita-se que isso ocorra devido às oscilações hormonais ocorridas, principalmente, no período pré-menstrual (BRENTANO et al., 2008; DATSON et al., 2014).

Conforme o exercício começa, o volume plasmático diminui. Essa redução é afetada pelo tipo e intensidade do exercício e pela postura utilizada. Como resultado, o volume plasmático associado ao exercício diminui gradualmente, o que pode ser compensado pela ingestão de líquidos durante o exercício (MOREIRA et al., 2006).

Quando a temperatura e a umidade ambiente são altas, a capacidade de manter a atividade física é reduzida, neste caso, o processo de desidratação e seu efeito no 
mecanismo de regulação da temperatura são importantes determinantes da fadiga. Para Lima et al. (2007):

\begin{abstract}
A elevação da temperatura corporal pode prejudicar as respostas fisiológicas e o desempenho físico produzindo risco à saúde. Essa perda ocorre principalmente pelo suor, que é a mais importante forma de dissipar calor. A produção de suor pode levar a hipo-hidratação, ocorrendo diminuição da performance, comprometimento do sistema cardiovascular e uma demanda do suprimento de sangue para a pele e músculo além de ocorrer alterações na função renal e nos hormônios associados com a retenção de fluído e sódio (LIMA et al., 2007).
\end{abstract}

Portanto, é recomendado que os atletas comecem a se exercitar após a hidratação total, e o estado de hidratação pode prevenir o estresse por calor, retardar a desidratação, aumentar a sudorese durante o exercício e minimizar o aumento da temperatura central, melhorando assim o desempenho esportivo (WEBBER et al., 2009).

Segundo Pinto et al. (2014), o objetivo do treinador é levar os atletas a melhores resultados. O controle fisiológico do corpo humano durante o exercício físico pode prevenir o consumo muscular, controlar o glicogênio hepático e prevenir a desidratação. $\mathrm{O}$ estado de hidratação é um fator decisivo para a prática de exercícios físicos.

Atualmente, vários métodos de avaliação de hidratação são usados: marcadores simples (cor e peso da urina), marcadores complexos (água sistêmica e osmolalidade plasmática), análise de amostra de sangue e outros marcadores (concentração de hemoglobina e hematócrito, sódio plasmático e sede) (PINTO et al., 2014).

Os atletas lutadores perdem peso principalmente antes da competição. No dia da pesagem, um peso além do que pode ser previsto nesta categoria causará uma desclassificação, o que obriga o atleta a perder peso em poucas horas (ROSSI, 2015).

A maioria dos atletas tende a perder peso significativamente alguns dias ou mesmo horas antes de pesar (KININGHAM; GORENFLO, 2015). Steen e Brownell, (2015) descobriram que mesmo depois que os órgãos e instituições médicas soaram o 
alarme, a forma de perder peso permaneceu inalterada e os atletas continuaram a usar métodos perigosos.

Além disso, $68 \%$ dos atletas relatam que os treinadores esportivos são as pessoas que orientam a PPR, e apenas $26 \%$ dos atletas recebem orientação de um nutricionista (BRITO et al., 2012).

O estudo realizado por Artioli et al. (2011) objetivou determinar o intervalo de tempo entre a pesagem e o início da competição num torneio oficial de Judô em São Paulo. O tempo médio entre a pesagem e o início da luta é de aproximadamente 4 horas. Entender a importância do tempo aproximado de recuperação que um atleta tem entre a pesagem e a primeira luta permite um melhor planejamento em como usar esse tempo para maximizar seu desempenho.

A perda de água no corpo pode levar a um estado de desequilíbrio hídrico, ocasionando efeitos fisiológicos adversos, patologia e morte. Quando excessiva (3\% a 5\% do peso corporal), a desidratação pode levar à diminuição da força e resistência muscular, diminuição do débito cardíaco, diminuição do volume de ejeção, diminuição da regulação da temperatura corporal, diminuição do fluxo sanguíneo e filtração renal e diminuição das reservas de glicogênio, assim como perda de eletrólitos (BORDIGNON, ESCOBAR, 2015)

Segundo Kleiner e Robinson (2009), a desidratação prejudica o desempenho físico, reduzindo-o em $48 \%$ e aumentando o perigo de distúrbios causados pelo calor, como cãibras e exaustão.

Uma simples desidratação leve pode causar desconforto e fadiga, enquanto altos níveis de desidratação podem causar um declínio significativo nas funções do corpo, levando a uma diminuição no volume sanguíneo, débito cardíaco, pressão arterial e, finalmente, redução da regulação da temperatura corporal (LORENÇO-LIMA, 2013). A temperatura retal de atletas desidratados pode ser maior do que a temperatura retal de atletas com hidratação normal (RIBEIRO; LIBERALI, 2015). 
A PPR pode desencadear inúmeras alterações como o desequilíbrio hormonal, imunossupressão, alteração do sistema cardiovascular, desequilíbrio hidroeletrolítico, diminuição da função renal, retardos no crescimento e desenvolvimento de atletas jovens, déficits cognitivos, diminuição no conteúdo de glicogênio muscular, diminuição do estado nutricional proteico e alterações metabólicas (LORENÇO-LIMA, 2010).

Segundo Bordignon; Escobar, (2015) apud Fogelholm (1994), o desempenho anaeróbio e a força muscular comumente têm uma redução após a PPR, com ou sem reidratação de 1 a 3 horas. Esse desempenho é mantido após um teste de 5 a 24 horas de reidratação. Isso não ocorre quando o peso é reduzido gradualmente, pois o desempenho anaeróbico não é afetado e a força pode aumentar.

A água, sucos naturais, bebidas refrescantes e a água isotônica são soluções utilizadas como reidratantes. Beber bebidas carbonatadas durante o exercício pode causar dores de estômago e bebidas alcoólicas podem causar desidratação, o que pode prejudicar o desempenho dos atletas (CRUZ et al., 2009).

A recuperação após o exercício completo envolve alguns processos fisiológicos, como restauração das funções fisiológicas normais, redução da dor muscular, desaparecimento dos sintomas físicos relacionados à fadiga e restauração das reservas de líquidos e energia. A bebida pós-treino ideal deve conter carboidratos para complementar o glicogênio muscular e o armazenamento de sódio (SILVA et al., 2015).

\section{METODOLOGIA}

O levantamento bibliográfico foi realizado por meio de consulta às bases de dados eletrônicas: Scielo, ScienceDirect e Google Scholar e outros documentos disponibilizados na web pelos próprios autores ou instituições, além de dissertações de mestrado e teses de doutorado. O levantamento dos dados foi feito entre agosto e setembro de 2020. Um total de 82 artigos foram pré-selecionados. Como critérios de inclusão, foram priorizados artigos dos últimos 15 anos (2005 a 2020) e que abordaram de forma mais específica o tema proposto. Foram excluídos artigos que 
não abordaram de forma específica a PPR em atletas de artes marciais. No total, foram selecionados 19 artigos que abordassem a combinação das seguintes palavraschaves: artes marciais, desidratação, rápida, perda e peso.

Em seguida, foi realizada uma pesquisa de campo, estruturada na plataforma Google Forms. Nesta plataforma foi elaborado um questionário com perguntas referentes ao tema proposto e enviado digitalmente via link aos participantes, escolhidos aleatoriamente e com plena consciência de participação. A amostra usada na pesquisa foi colhida dos lutadores de diferentes modalidades de artes marciais (em sua grande maioria de jiu-jitsu) e categorias de peso, de modo a se conseguir representar a população descrita.

Com isso, obteve-se dados quantitativos que ilustraram e responderam às perguntas do questionário, permitindo, através de técnicas estatísticas, especialmente por gráficos, inferir quais grupos, em quais características e quais modalidades praticam ou não as técnicas de PPR, quais suas consequências em um nível pessoal de observação empírica e qual a motivação dos que chegaram a praticar.

questionário foi composto por 12 (doze) questões de múltipla escolha que permeavam entre existência ou não das práticas de desidratação, possíveis motivos, retorno à prática e afins. O questionário foi aplicado a 37 praticantes de artes marciais que o respondeu voluntariamente.

A partir do questionário aplicado, foi possível inferir algumas informações. Como dito anteriormente, o questionário foi de múltipla escolha e abordou as seguintes questões:

1. Sexo

2. Idade

3. Artes Marcias praticadas

4. Você participa ou já participou de competições?

5. Em qual categoria de peso você participa ou participou?

6. Você já utilizou alguma técnica de perda de peso rápida antes da uma competição? Qual? 
7. Após a prática de rápida perda de peso, você sentiu algum/alguns do/s efeito/s abaixo?

8. O que te levou querer perder peso rapidamente?

9. Você sabia dos riscos da rápida perca de peso?

10. Após perder peso rapidamente, você o recuperou?

11. Ao perder peso, você sentiu algum dos efeitos abaixo?

12. Você voltaria a utilizar técnicas de rápida perda de peso?

Após finalizar a aplicação do questionário, foi feita uma análise detalhada das respostas para, então, apresentar uma conclusão que será abordada nos resultados e discussões.

\section{RESULTADOS E DISCUSSÕES}

Como já dito, o questionário foi aplicado para 37 pessoas que o responderam voluntariamente, sendo 9 mulheres e 28 homens (gráfico 1). Todos os gráficos apresentam o número de indivíduos em cada questão respondida.

Gráfico 1 - Relação dos participantes por gênero

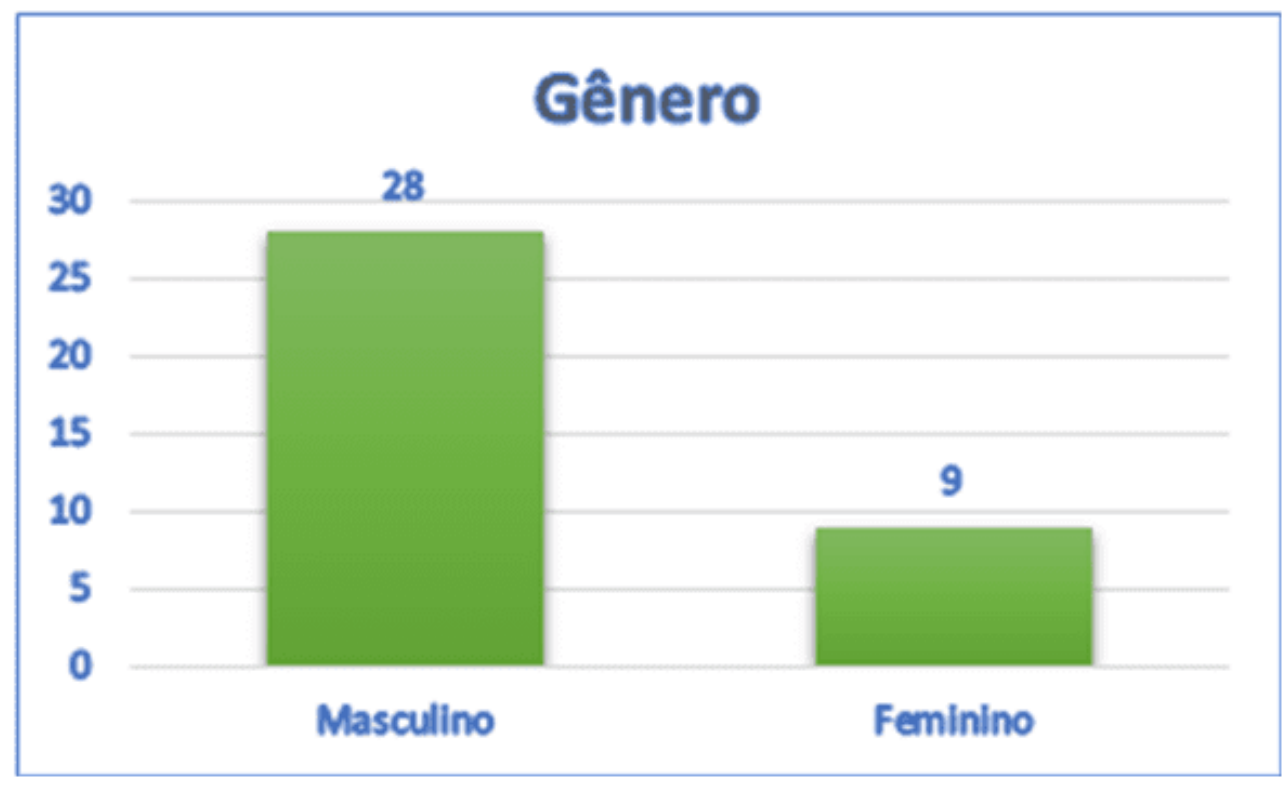

Fonte: elaboração dos autores (2021) 
Quanto a idade dos participantes, em sua maioria, ficou entre 19 e 26 anos de idade (gráfico 2).

Gráfico 2: Relação dos participantes por idade

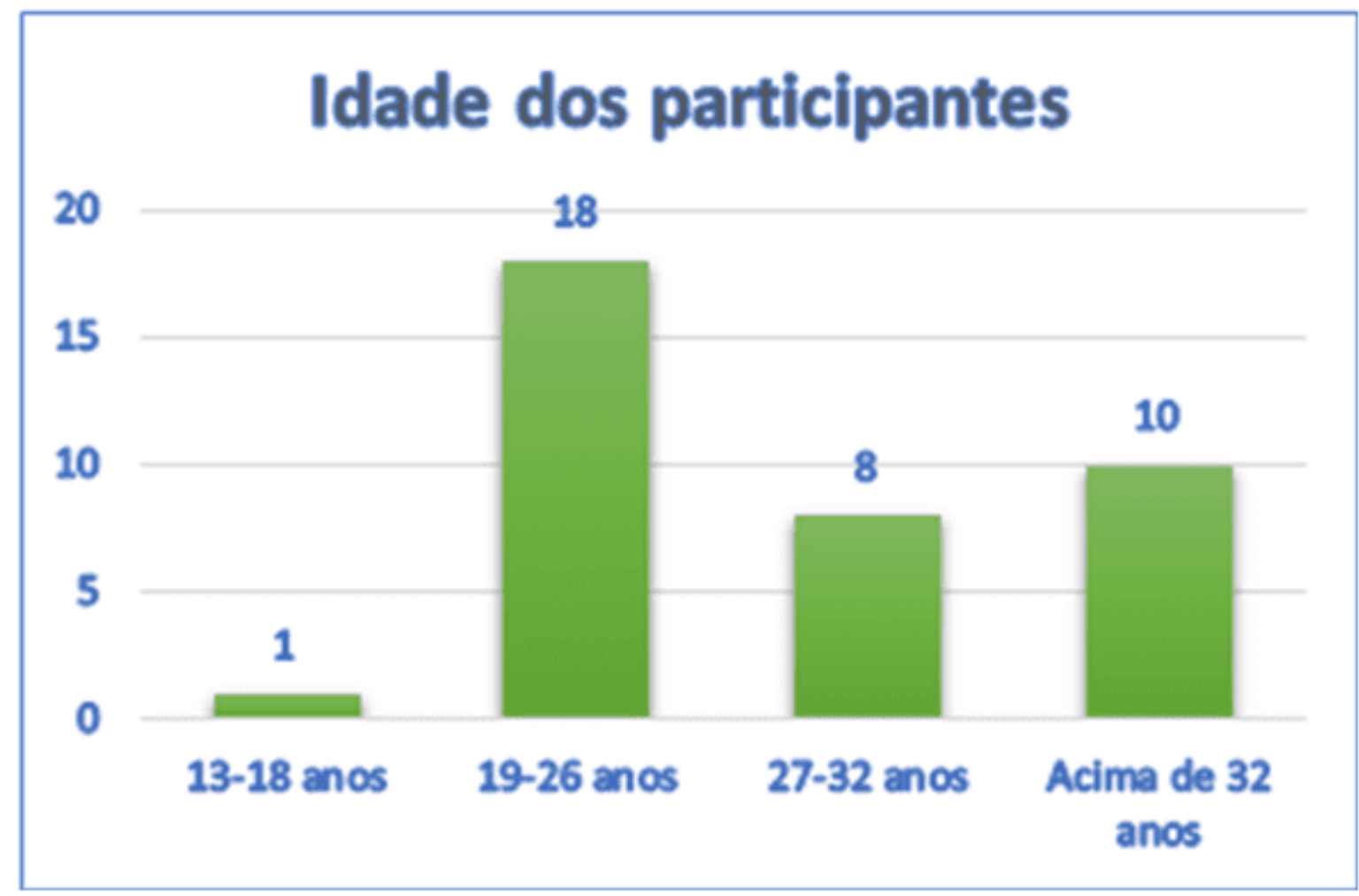

Fonte: elaboração dos autores (2021)

Houve uma prevalência de praticantes de jiu-jitsu durante a pesquisa, em relação a outras modalidades de artes marciais. (gráfico 3). 
Gráfico 3: Relação das artes marciais praticadas pelos participantes

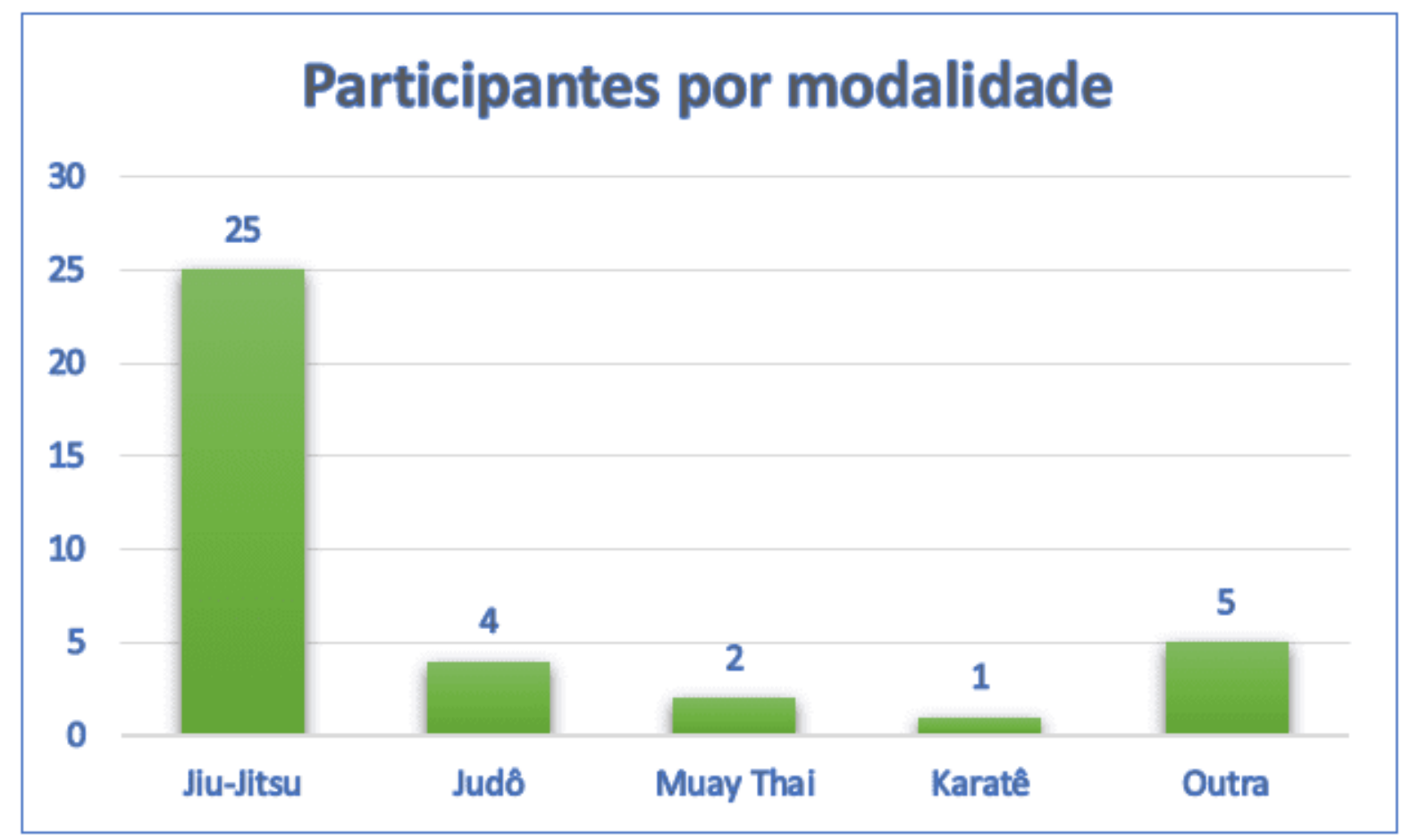

Fonte: elaboração dos autores (2021)

Dos participantes da pesquisa, 92\% já afirmaram ter participado de competições esportivas dentro da arte marcial praticada (gráfico 4). As categorias de pesos foram separadas de 10 em $10 \mathrm{~kg}$ (gráfico 5). 
Gráfico 4: Participação em competições

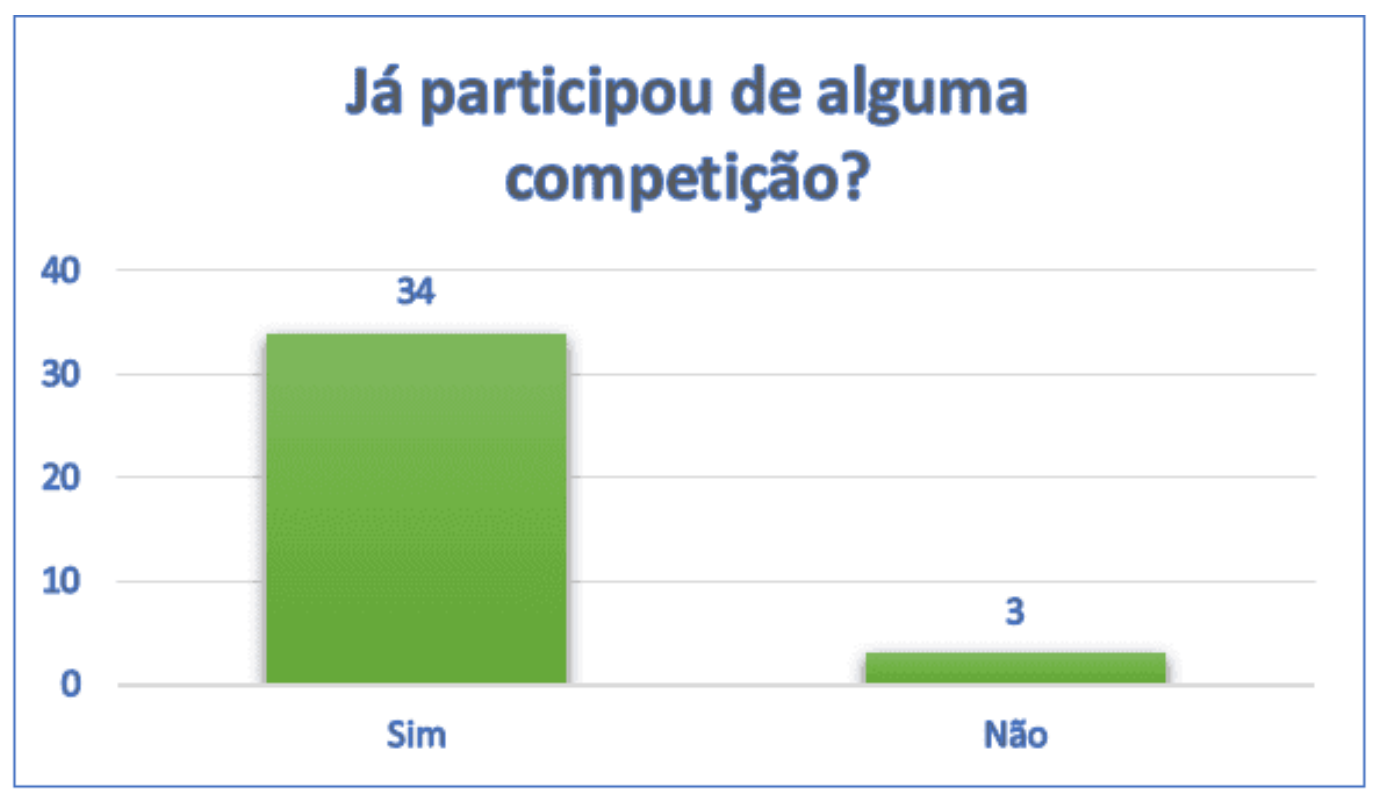

Fonte: elaboração dos autores (2021)

Gráfico 5: Relação das categorias competidas pelos participantes por peso

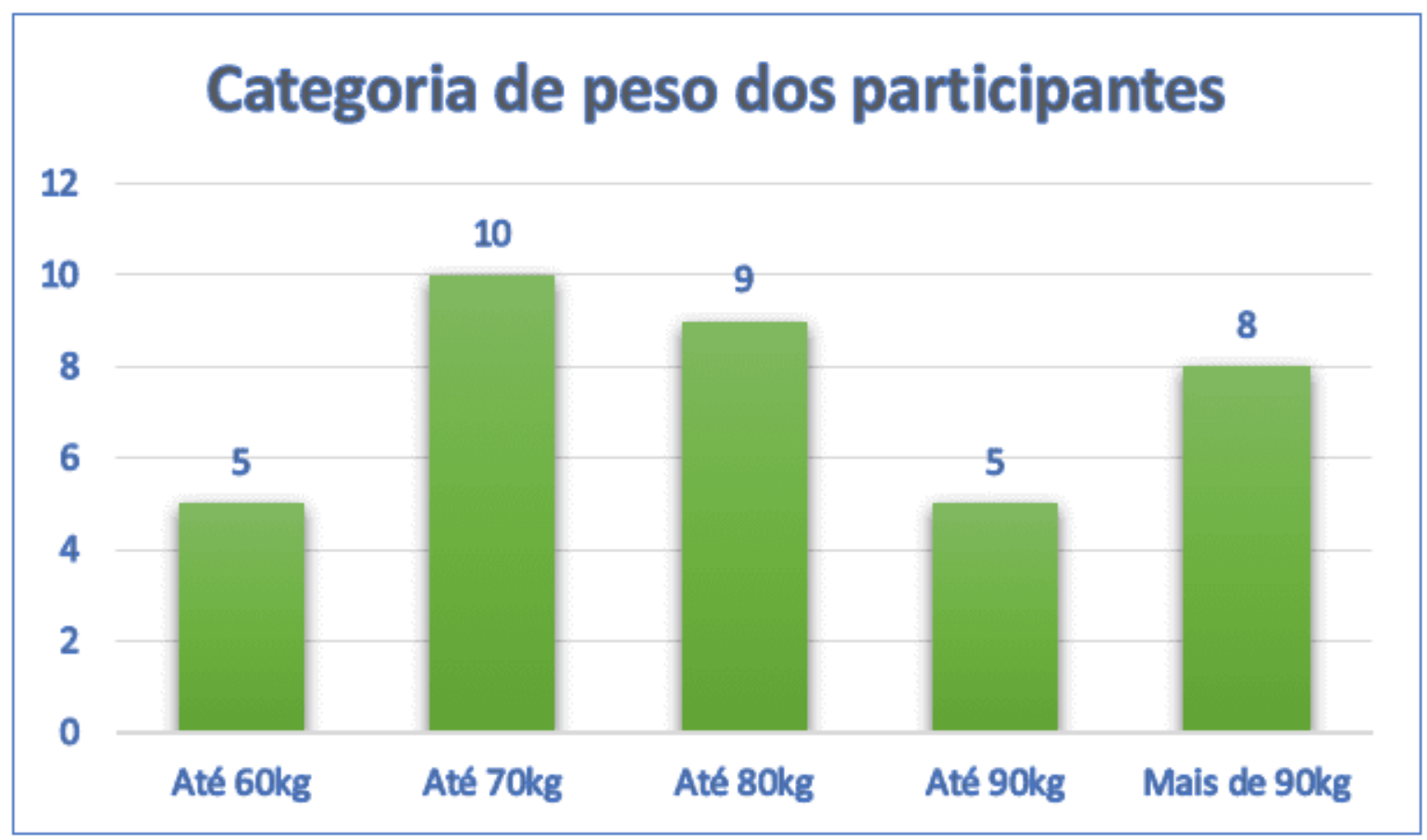

Fonte: elaboração dos autores (2021) 
Dentre os entrevistados, $46 \%$ afirmaram nunca terem usado métodos de PPR (gráfico 6). Dos que já fizeram algum tipo de método de PPR (20 atletas no total), $70 \%$ de terem praticado restrição alimentar, 24\% afirmaram terem usado o método da desidratação e $6 \%$ de algum outro método (gráfico 7). Dos que fizeram PPR, $48 \%$ notaram redução do desempenho atlético, 39\% observaram mudanças no humor e $13 \%$ perceberam mudanças no comportamento (gráfico 8 ).

Gráfico 6: Utilização de algum método de perda de peso rápida (PPR)

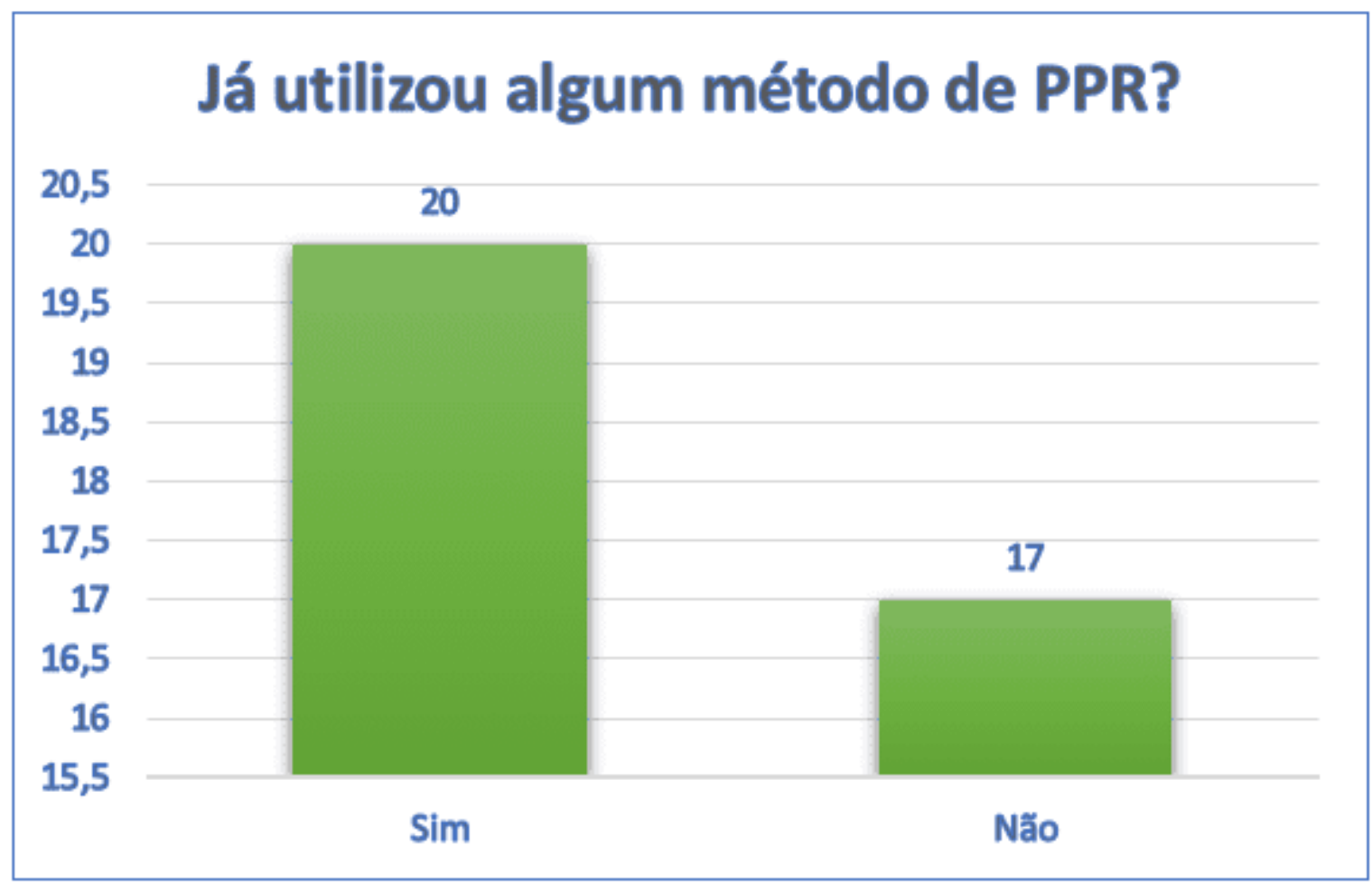

Fonte: elaboração dos autores (2021) 
Gráfico 7: Métodos utilizados para a perda de peso rápida (PPR)

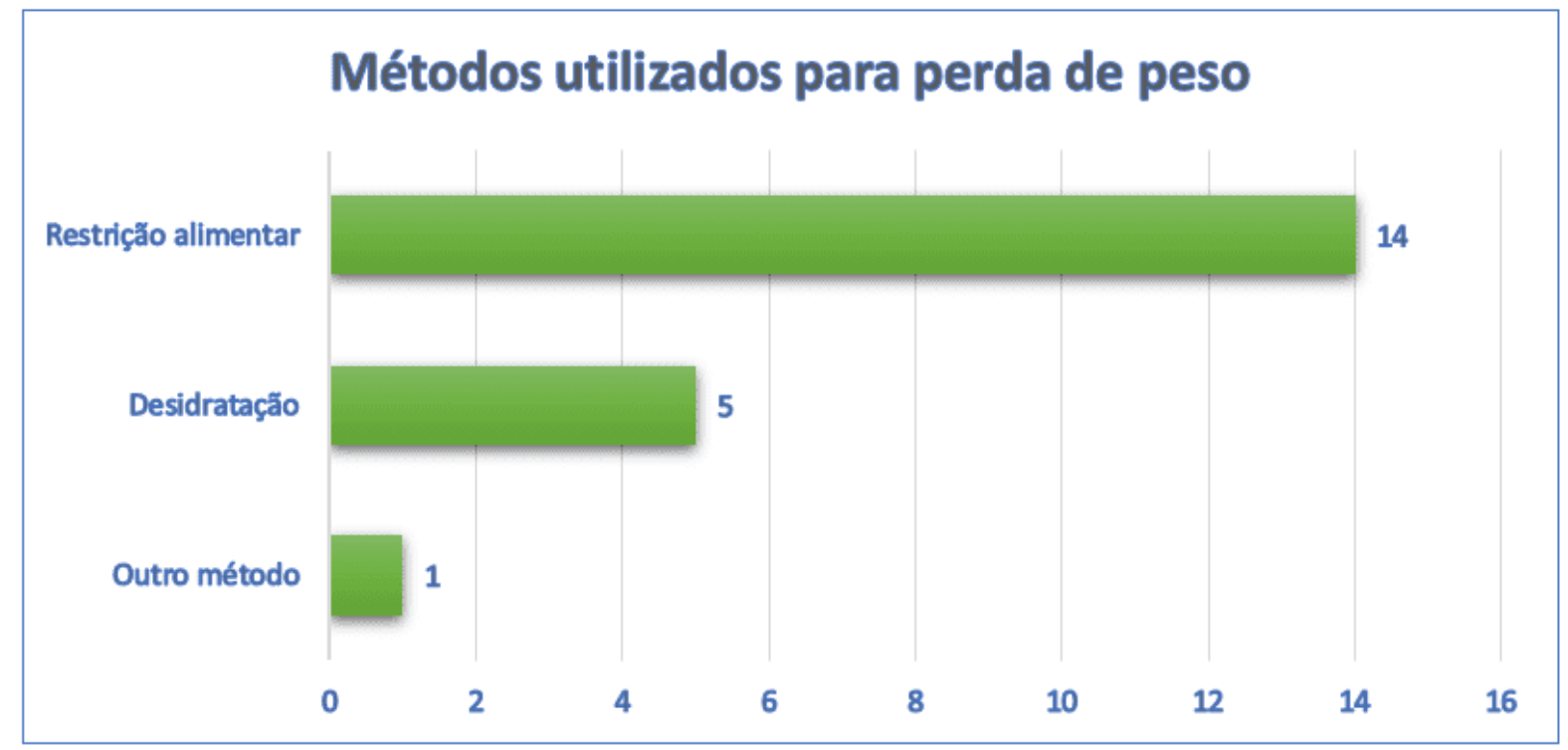

Fonte: elaboração dos autores (2021)

Gráfico 8: Alterações percebidas com a perda de peso rápida (PPR)

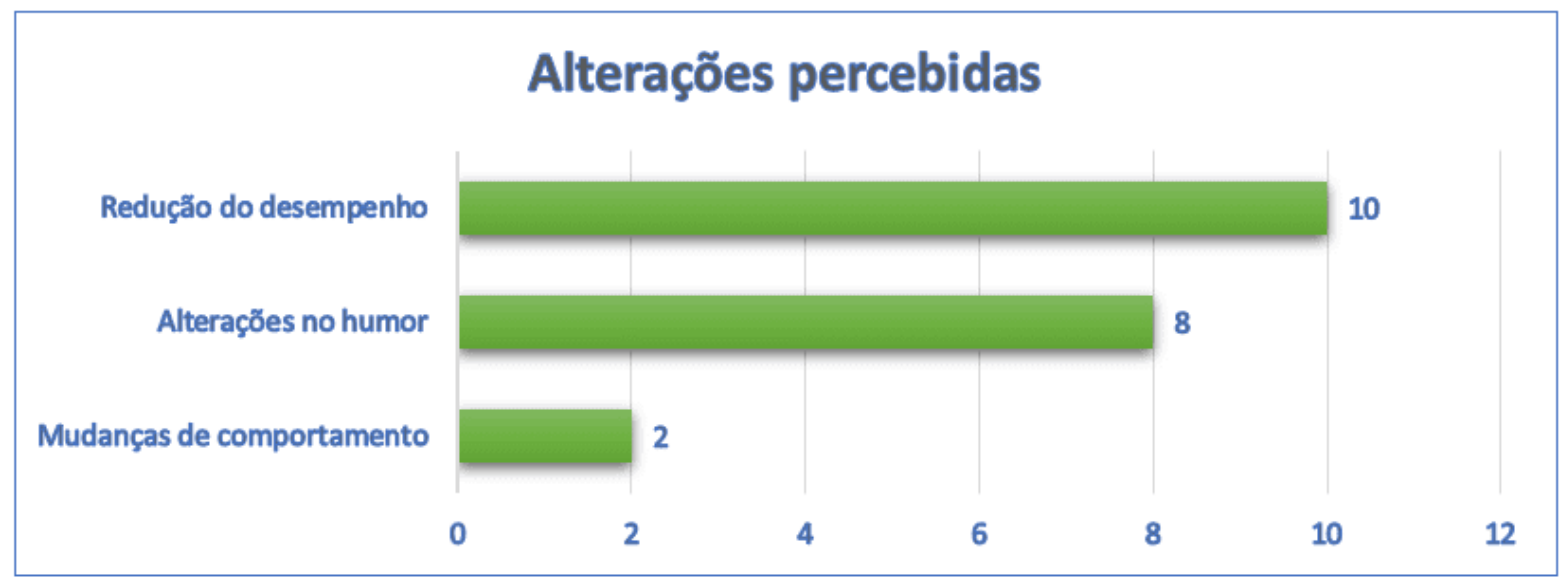

Fonte: elaboração dos autores (2021)

Quanto aos motivos que levaram à PPR (gráfico 9), 48\% dos participantes da pesquisa afirmaram que o fizeram por vontade de competir em outra categoria, $12 \%$ pelo caráter competitivo dos torneios, $12 \%$ por pressão dos colegas, $8 \%$ por pressão do professor/sensei/treinador e $20 \%$ por algum outro motivo. 
Gráfico 9: Motivos para realizar a perda de peso rápida (PPR)

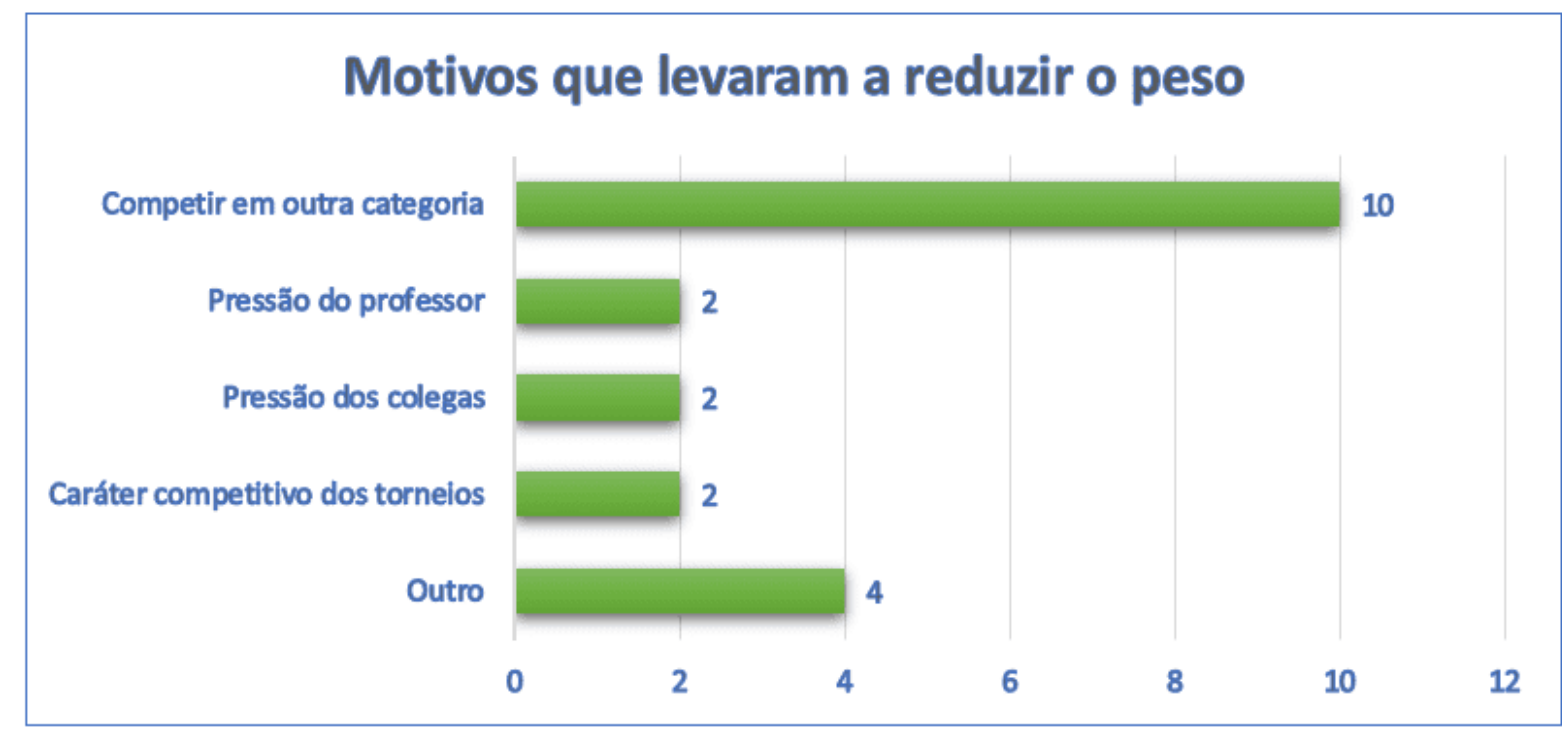

Fonte: elaboração dos autores (2021)

Dos entrevistados que perderam peso rapidamente, $41 \%$ afirmaram não saber dos riscos das práticas utilizadas (gráfico 10). Dos que fizeram uso da PPR, 65\% conseguiram recuperar o peso naturalmente, enquanto $26 \%$ recorreram a fatores externos e $9 \%$ não o recuperaram (gráfico 11). 
Gráfico 10: Conhecimento sobre os riscos da perda de peso rápida (PPR)

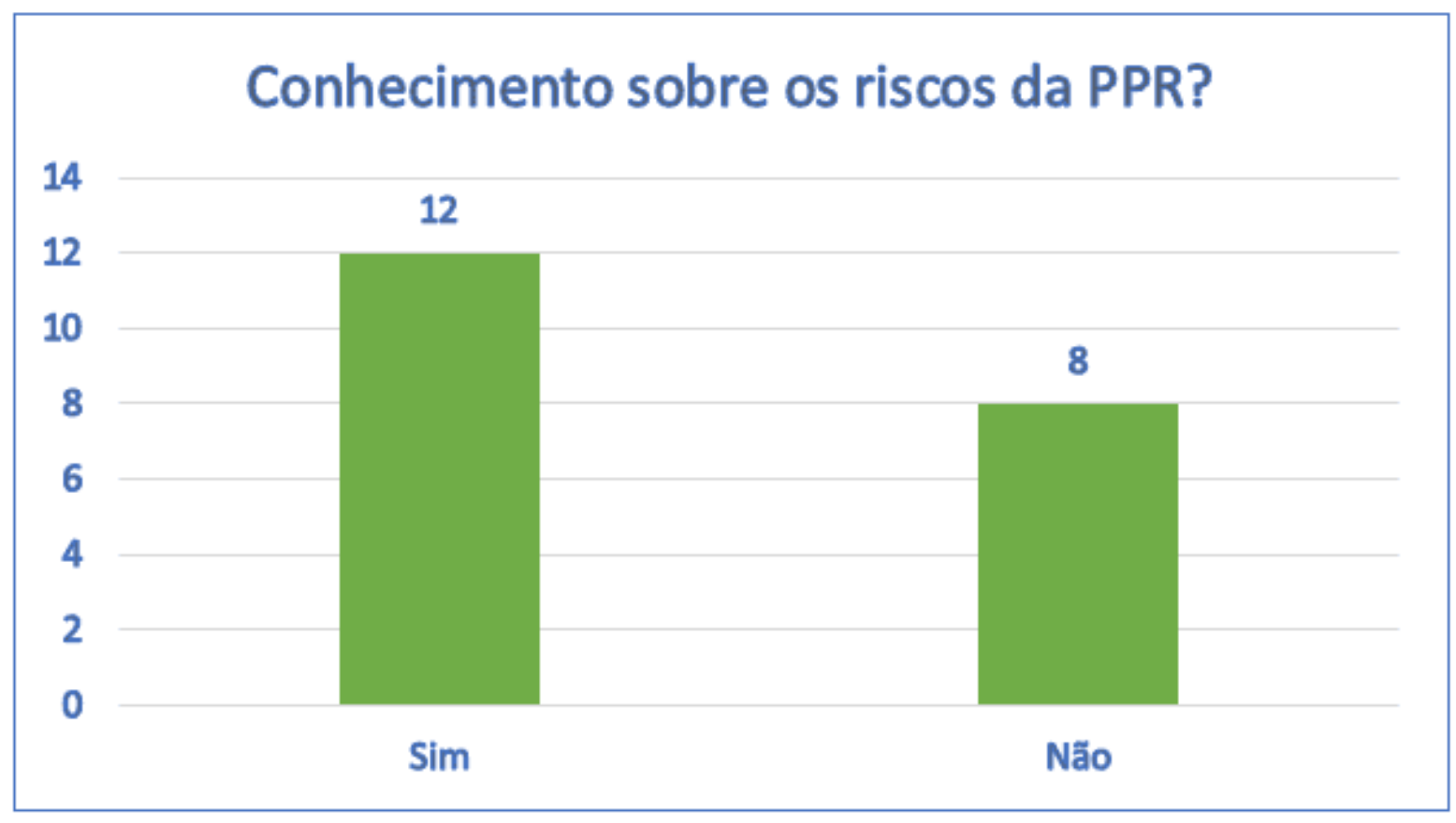

Fonte: elaboração dos autores (2021)

Gráfico 11: Recuperação de peso após a perda de peso rápida (PPR)

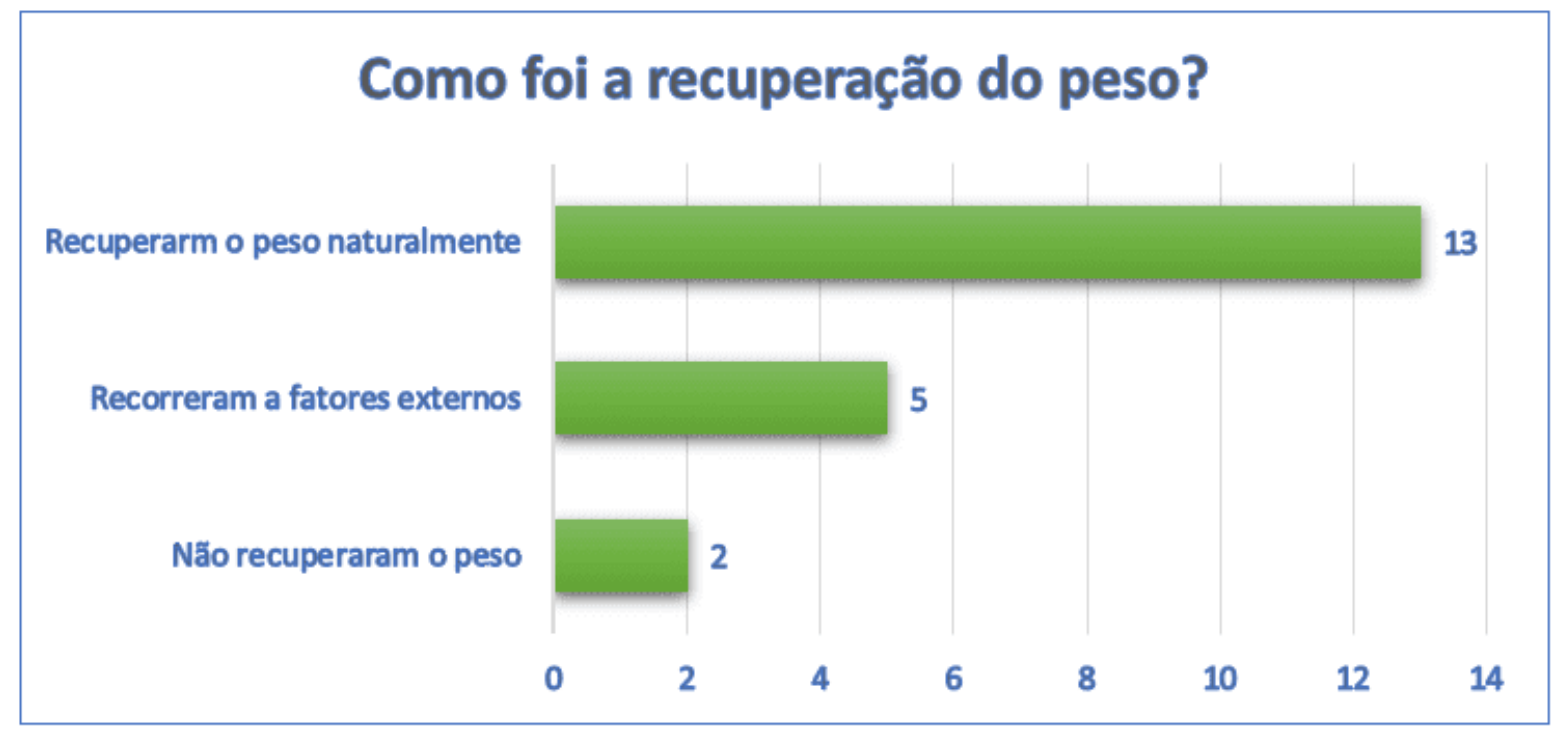

Fonte: elaboração dos autores (2021)

Os efeitos da perda de peso rápida (PPR) são observados no gráfico 12. 
Gráfico 12: Efeitos da perda de peso rápida (PPR)

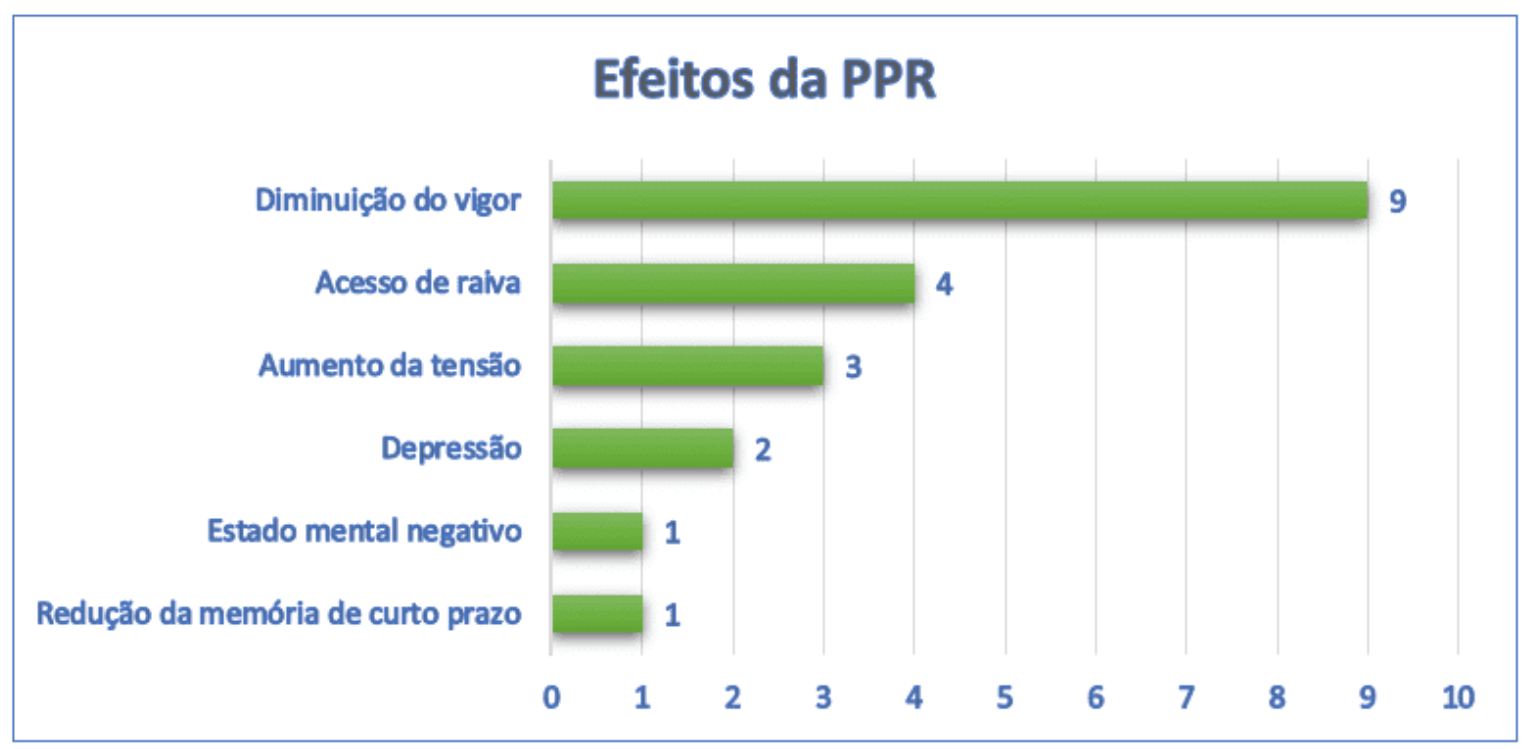

Fonte: elaboração dos autores (2021)

Quando perguntados sobre retornarem a praticar as mesmas ações, 35\% dos participantes afirmaram que repetiriam os procedimentos, $24 \%$ que não voltariam a praticar. $8 \%$ afirmaram que nunca praticaram e não pretendem praticar, contudo $33 \%$ dizem que, mesmo nunca tendo perdido peso com algum desses métodos, ocasionalmente utilizariam (gráfico 13). 
Gráfico 13: Sobre o uso da perda de peso rápida (PPR) e seu possível uso no futuro

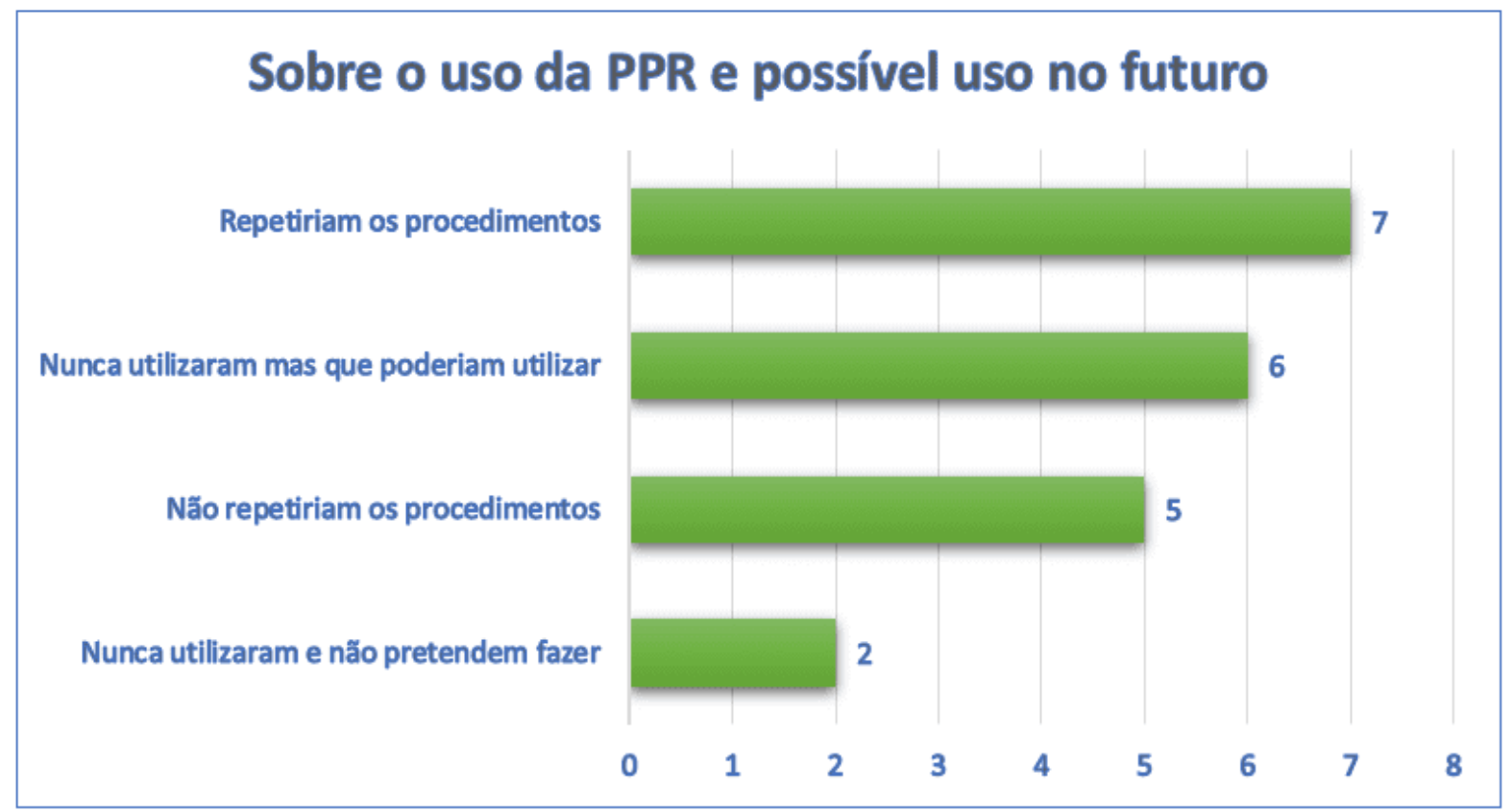

Fonte: elaboração dos autores (2021)

Conforme observado nos dados encontrados na pesquisa, o uso da PPR é comum no meio dos atletas de artes marciais e nos dados dessa amostra, $54 \%$ dos entrevistados já praticaram algum método de PPR, sendo que entre esses, 70\% fizeram restrição alimentar, $24 \%$ afirmaram terem usado o método da desidratação e $6 \%$ de algum outro método.

$\mathrm{Na}$ amostra estudada, $48 \%$ dos participantes que fizeram PPR afirmaram que a fizeram por vontade de competir em outra categoria. Isso corrobora com os estudos de Sundgot-Borgen et al. (2013) que afirmaram que os atletas fazem PPR por acharem que teriam algum tipo de vantagem sobre seu adversário lutando numa categoria de peso inferior à própria.

Dos atletas da amostra que afirmaram ter feito PPR, 48\% notaram redução do desempenho atlético, 39\% observaram mudanças no humor e 13\% perceberam mudanças no comportamento, corroborando com os sintomas descritos por Lima et al. (2007); Kleiner; Robinson (2009); Rossi et al. (2010); Lorenço-Lima (2013); Bordignon; Escobar (2015), sendo eles: diminuição da força e resistência muscular, 
diminuição do débito cardíaco, diminuição do volume de ejeção, diminuição da regulação da temperatura corporal, diminuição do fluxo sanguíneo, diminuição das reservas de glicogênio, perda de eletrólitos e redução das atividades imunológicas, cognitivas e sensoriais.

\section{CONSIDERAÇÕES FINAIS}

Este estudo permitiu, através da pesquisa de campo realizada e da revisão de literatura em artigos científicos, teses de doutorado e dissertações de mestrado, ao que se refere à PPR em atletas praticantes de artes marciais, analisar e descrever o cenário das lutas em uma perspectiva histórica e atual. Através do questionário respondido por praticantes de artes marciais, como proposta de pesquisa de campo, foi possível observar na prática todas as teorias e afirmações encontradas na revisão de literatura.

Foi possível perceber que, dentro da amostra analisada, grande parte dos voluntários dessa pesquisa, já participaram de alguma competição, em sua maioria de Jiu-Jitsu, e desses, uma boa porcentagem realizou métodos não indicados de PPR.

A prática de técnicas de PPR é muito utilizada no âmbito das artes marciais, visando uma vantagem sobre os seus adversários e para se adequar a uma categoria de peso específica. Algumas modalidades oferecem a possibilidade da pesagem com um dia de antecedência, mas boa parte das modalidades fazem a pesagem no dia ou mesmo, momentos antes do início da competição. Mesmo com o conhecimento do risco da PPR pela maioria dos entrevistados, essa prática continua tendo muitos adeptos.

Diante disso, esta pesquisa teve como problema: quais as consequências físicas e psicológicas para o atleta que faz uso da PPR? Pode-se afirmar que os efeitos colaterais condizentes com a literatura foram relatados pelos indivíduos da amostra que fizeram a PPR, sendo que dos atletas pertencentes a amostra que afirmaram ter feito PPR, 48\% notaram redução do desempenho atlético, 39\% observaram mudanças no humor e $13 \%$ perceberam mudanças no comportamento. Todavia, mesmo após sentirem efeitos negativos em sua saúde e descobrirem sobre todos os 
riscos, $35 \%$ dos entrevistados voltaria a praticar os métodos. Entre aqueles que nunca praticaram, fariam uso da PPR, caso necessário.

As causas que levam os atletas a realizarem tais atos são variados, mas a grande maioria apontou vontade de competir em categorias nas quais não se encaixam. A maioria dos estudos envolvendo a PPR em atletas de esportes competitivos mostra que grande parte dos lutadores usa a perda de água como uma estratégia para baixar o peso, limitando a ingestão de água, além de estimular o suor e o excesso de atividades diuréticas. Além disso, restrição da ingestão calórica é muito utilizada. Em alguns casos, a combinação da perda de água com a restrição calórica também é muito comum.

Os resultados encontrados corroboraram com os identificados previamente, o que demonstra que é necessária uma atenção maior às necessidades dos competidores.

Para reduzir o risco dos atletas, as decisões sobre perda de peso devem basear-se em recomendações mais seguras e de médio e longo prazo: o atleta deve pesar-se frequentemente; a perda de peso deve ocorrer nas fases de treinamento; a comissão técnica, nutricionista, médico e atleta devem planejar metas para perda de peso individualizadas.

Limitações da pesquisa: essa pesquisa apresenta limitação no número de entrevistados devido ao fato de ter sido realizada no ano de 2020, auge da pandemia da Covid-19 no Brasil. Devido a decretos, muitos centros de treinamento estavam fechados e os atletas/praticantes das artes marciais não estavam treinando. Pesquisas futuras em tempos de normalidade, fora da pandemia poderiam contribuir com um número maior de participantes, inclusive com um questionário mais aprimorado.

\section{REFERÊNCIAS}

ARTIOLI et al. Tempo de recuperação entre a pesagem e o início das lutas em competições de judô do Estado de São Paulo. Revista Brasileira de Educação Física e Esporte, São Paulo, v.25, n.3, p.371-76, 2011. 
AWI, F. Filho teu não Foge à Luta: Como os Lutadores Brasileiros Transformaram MMA em um Fenômeno Mundial. Intrínseca. Rio de Janeiro. 2012. p. 24-29.

BORDIGNON, Natália Guerra; ESCOBAR Mariana. Esportes de combate: métodos de perda de peso e aspectos nutricionais. Ciência em Movimento - Reabilitação e Saúde. v. 17, n. 35 (2015)

BRENTANO, M. A.; CADORE, E. L.; SILVA, E. M.; SILVA, R. F.; KRUEL, L. F. M. Estimativa de força máxima em exercícios de musculação baseados em parâmetros antropométricos de homens e mulhers fisicamente ativos. Revista Brasileira de Motricidade. Vol. 2, №. 4, p. 294-301, 2008.

BRITO et al. Methods of Body-Mass Reduction by Combat Sport Athletes. International Journal of Sport Nutrition and Exercise Metabolism, v. 22, p. 89 -97, 2012.

CARVALHO, T.de; MARA, L.S.de. Hidratação e Nutrição no Esporte. Revista Brasileira de Medicina do Esporte, Florianópolis; SC, v.16, n.2, p.144-148. Mar/Abr, 2010.

CRUZ, M.A.E.; CABRAL, C.A.C.; MARINS, J.C.B. Nível de conhecimento e hábitos dos atletas de mountain bike. Fitness Performance Journal. Rio de Janeiro, v.8. n. 2. p. 79-89. 2009.

DATSON, N.; HULTON, A.; ANDERSSON, H.; LEWIA, T.; WESTON, M.; DRUST, B.; GREGSON, W. Applied physiology of female soccer: an uptade. Sports Med. Vol. 44. Num. 9. p.1225-1240. 2014.

FABRINI, S. P.; BRITTO C. J.; MENDES E. L.; SABARENSE C. M.: MARINS J. C. B.; FRANCHINI E. Práticas de redução de massa corporal em judocas nos períodos pré competitivos. Revista Brasileira de Educação Física e Esportes. 2010; 24(2): 165177. 
IDE, Bernardo N. Considerações sobre a redução da massa corporal antes das competições nas modalidades desportivas de luta. EF Desportes Revista Digital, Buenos Aires, ano 10, n. 75, 2004.

LORENÇO-LIMA, L. et al. Comportamento do dano muscular em uma simulação de competição de jiu-jítsu. In: CONGRESSO INTERNACIONAL DE EDUCAÇÃO FíSICA, ESPORTE E LAZER, 2., Presidente Prudente, 2010. Anais ... Presidente Prudente: UNESP, 2010. p. 551-551.

LORENÇO-LIMA, Leandro de; HIRABARA, Sandro M. Efeitos da perda de peso em atletas de combate. Revista Brasileira de Ciências do Esporte, Florianópolis, v. 35, n.1, p. 245-260, 2013.

MOREIRA, Wagner Wei et al. Educação Física e esportes: perspectivas para o século XXI. 13. ed. São Paulo: Papirus, 2006.

PINTO, S. da F.; BERDACKI, V.S.; BIESEK, S. Avaliação da Perda Hídrica e do Grau de Conhecimento em Hidratação de Atletas de Futebol Americano. Revista Brasileira de Nutrição Esportiva, São Paulo, v.8. n. 45.p. 171-179. Maio/Jun. 2014. ISSN 19819927.

ROSSI, L.; REIS,

V. A.; AZEVEDO,

C.

O.

Desidratação e recomendações para a reposição hídrica em crianças fisicamente ativas. Revista Paulista de Pediatria. Vol.28.337-345. 2010.

SANTOS JÚNIOR, R. B. Perda de peso em atletas brasileiros de artes marciais mistas MMA: prevalência, magnitude, métodos e sintomas vivenciados. Dissertação de Mestrado. Universidade Federal do Paraná. Paraná. 2016.

SILVA, Thiago Eduardo Limeira da; SILVA, Maria Gilvanira Gomes da; ESPÍNDOLA, Wilma Cléa Ferreira. Os benefícios do jiu-jitsu para a saúde: um incentivo para a prática esportiva. Revista Científica da FASETE. 2015. 
SUNDGOT-BORGEN, J.; MEYER, N.L.; LOHMAN, T.G.; ACKLAND, T.R.; MAUGHAN, R.J.; STEWART, A.D.; MULLER, W. How to minimise the health risks to athletes who compete in weight-sensitive sports review and position statement on behalf of the Ad Hoc Research Working Group on Body Composition, Health and Performance, under the auspices of the IOC Medical Commission. British Journal of Sports Science. Vol. 47. Num. 16. 2013. p. 1012-1022.

VASQUEZ, D. G. As Artes Marciais Mistas (MMA) Como Esporte Moderno: Entre a Busca da Excitação e a Tolerância à Violência. Esporte \& Sociedade. Vol. 8. Núm. 22. 2013.

Enviado: Julho, 2021.

Aprovado: Dezembro, 2021. 